\title{
40. INVESTIGATION OF MINOR METEOR STREAMS
}

\author{
A. K. TeREnTEVA \\ (Kiev State University, U.S.S.R.)
}

\begin{abstract}
A BSTRACT
The paper consists of three sections:

(1) In continuation of a previous paper by the author, on 154 minor meteor streams, elements of orbits and other data are presented for an additional 95 minor streams (most of them less active). These streams have been found both by the studies of the photographic orbits of meteor bodies known before, and from the visual radiants of faint showers.

(2) The problems of a possible family of six minor meteor streams associated with the Lexell comet 1770-I, and the connection between nine other minor streams and long-period comets, are examined. The assumption is made that nearly-parabolic comets may be accompanied by meteor streams of considerable width.

(3) Radiants and elements of the orbits for $\mathbf{3 0}$ meteor bodies of the Cyclids are described, as were established by photographic data. Perturbed motion of one such meteor body is investigated by numerical integration of differential equations of motion on the electronic computer BESM-2, using Cowell's method of quadratures and taking account of perturbations from six planets (VenusUranus) and of high-order terms through to the 4th order. Over the time interval studied of 45 years the orbit of the Cyclids has been stable. Perturbing action of the Earth does not lead to any substantial changes in the elements of the orbits. Even at close approaches of the order of $0.003 \mathrm{AU}$ the changes in the angular elements are not greater than about $1^{\circ}$.
\end{abstract}

This paper is a continuation of the author's investigation (1966a) on minor meteor streams, based on the analysis of more than 3700 photographic orbits of individual meteor bodies, published before 1967 (from observations made since 1936), and on information from visual observations (those with velocity determination) of some 2000 radiants of faint showers during the 19th and 20th centuries.

\section{On 95 New Minor Meteor Streams}

The earlier paper - referred to above - contains detailed information about 154 minor streams, the majority of which are quite active. The orbits of these streams are now confirmed, and supplemented by later photographic observations, so that more than half are represented by 3-5 orbits, and about three score by 6-16 orbits.

Data supplied here concern an additional 95 minor streams found by the author. These are fainter showers, but on the whole no less reliable. The number of individual photographic orbits in each stream ranges from 3 to 11 for $28 \%$ of the streams, but is only 2 for $65 \%$.

Table 1 contains mean values of the coordinates for the corrected geocentric radiant 
$R_{\mathrm{g}}$, the extra-atmospheric velocity $V_{\infty}$, the heliocentric velocity $V_{\mathrm{h}}$, and the orbital elements from photographic determinations for 95 streams (Nos. 155-249). The date of each shower's activity has been found jointly from visual and photographic observations. The abbreviated designation of the shower (by the star next to the centre of the area of radiation) has been formed, as before, from the international three-letter designation of the constellation with addition of the ending - ds, for example, $\alpha$-UMids, 1H-Drads, 16-Lyrds, N-Hyads. Compound showers consisting of separate branches $(\mathrm{N}, \mathrm{Q}, \mathrm{S})$ or groups $(\mathrm{a}, \mathrm{b}, \mathrm{c})$ sometimes have been given double names, for instance, Peg-Sclds, CVn-Leods, $\alpha$-CVn-l-Antds.

The reference numbers of photographic meteors and visual radiants (from corresponding sources) referring to a given stream are listed in Table 2 for each stream. Reference numbers of separate meteors or visual radiants, that may bear some kind of relation to the stream, are shown in the column 'Notes'.

A question not yet investigated by us is the extent to which chance plays a part in finding the 95 streams. If every individual orbit were independent, the probability of the accidental coincidence of two such orbits with 5 elements, within the limits of deviations generally accepted as permissible, would be extremely small. But in reality the orbits possess a preferential distribution, concentration of inclinations to the ecliptical plane, and so on. On the other hand, many minor showers are well known from visual observations, so that a coincidence of their dates, velocities and positions of radiants, even with two photographic radiants, greatly increases the chances of the reality of a stream. Such considerations lead to the conclusion, that among the 95 minor streams the proportion of chance coincidences will be less than $1 / 5$.

It is well known that a meteor stream can cross the Earth's orbit twice - at the ascending node $\Omega$, and at the descending node $\mho$ of the orbit, if the argument of perihelion $\omega$ equals approximately $90^{\circ}$ or $270^{\circ}$. The streams Nos. 158, 159, 160, 189, $197,211,215,231,234,235,240$ and 242 satisfy these conditions with a permissible deviation of less than $10^{\circ}$. We succeeded in identifying the following pairs: Nos. 189 and 242, 193 and 240, 164, and 235. The meteor streams 193 and 240 form a single stream, about $0 \cdot 2 \mathrm{AU}$ in width, and with an orbit nearly perpendicular to the ecliptic plane. In the last case (long-periodical streams with reverse motion, Nos. 164 and 235) we must assume a considerable width of the stream, not less than $0.5 \mathrm{AU}$. This follows from the epochs of visibility and from the values of perihelion distances. Let us remember that there is an analogous phenomenon for the $\eta$-Aquarids and the Orionids, and the separation of the two nodes differs from $180^{\circ}$ by $18^{\circ}$ at least. The presence of an appreciable quantity of meteoric matter, dispersed over such a distance, makes it possible to assume that the parent comet was at one time of considerable size. In this case it was Halley's Comet, and other examples are the comet Encke, which has given rise to the Taurids, and the now unknown comet which formed the $\delta$-Aquarids. The same may be said with respect to some minor streams found by us. Planetary perturbations increase the width of a stream of course, and if the concentration of 


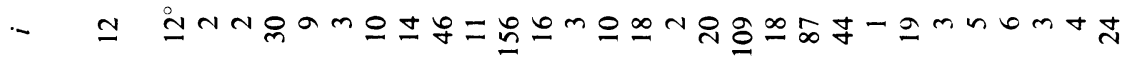

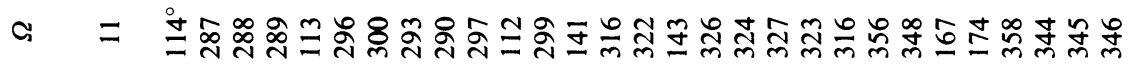

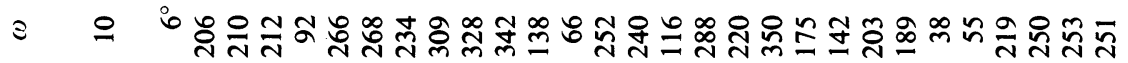

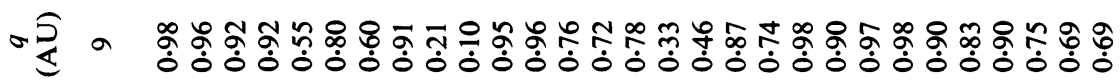

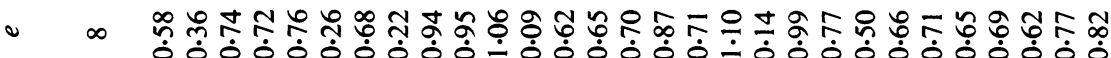

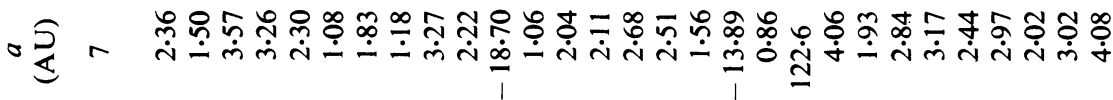

$د$ 递

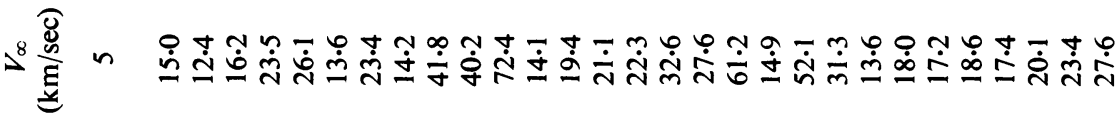

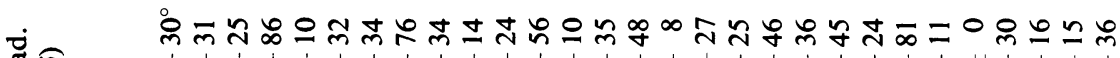

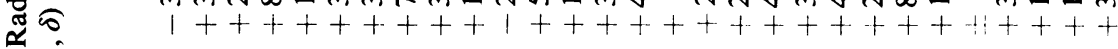

i $\sum_{0}^{\infty}+$

ర゚

总

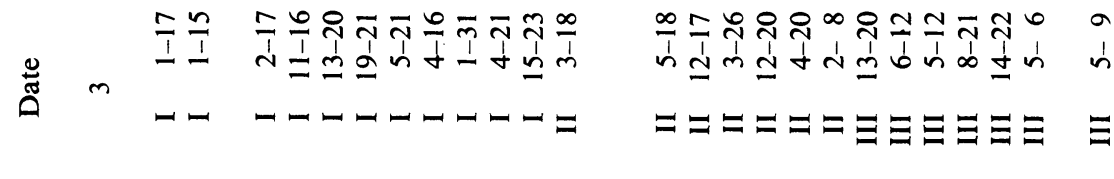

ఏอ

తิతిอ

ฮิ อิ

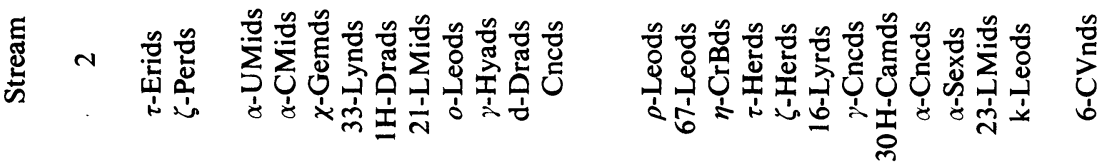

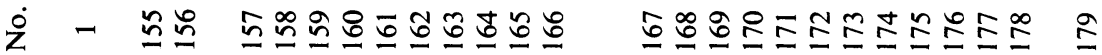


エ

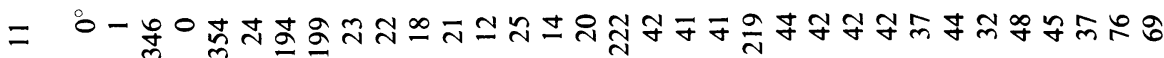

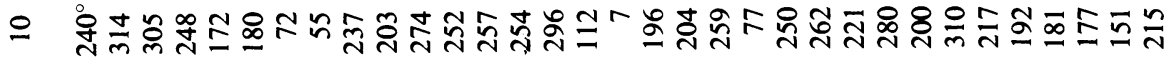

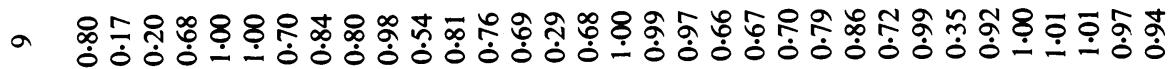

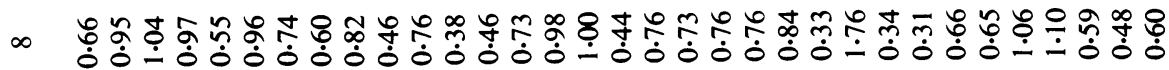
-

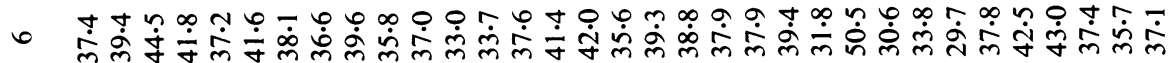

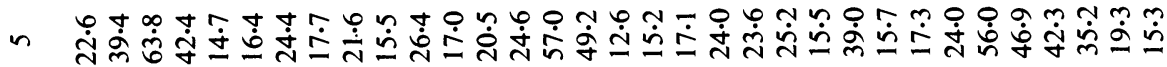

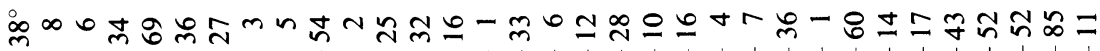
$\checkmark$

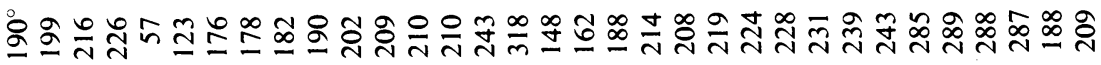

\begin{tabular}{|c|c|c|c|c|}
\hline$\Xi \Xi \Xi \geq \geq \geq$ & $\geq \Xi$ & $\geq \Xi \geq \geq \geq$ & $\geq$ & $\geq \geq>\geq \geq \geq \geq$ \\
\hline
\end{tabular}

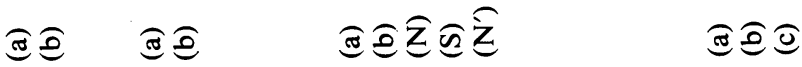

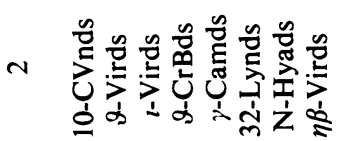

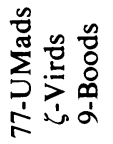

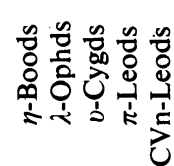

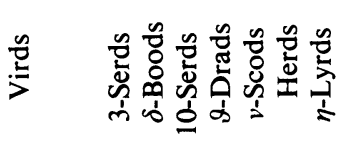

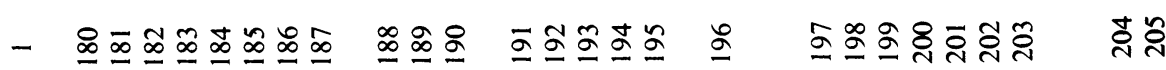

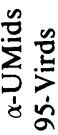




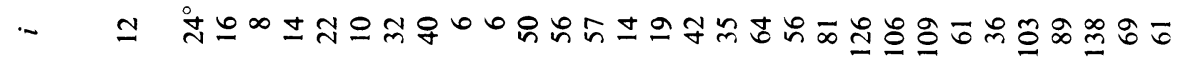

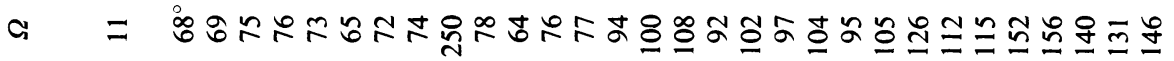

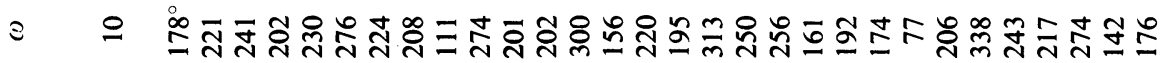

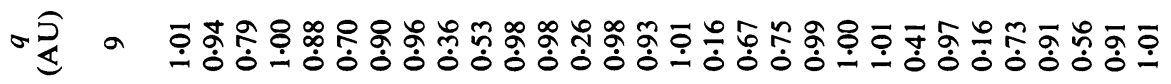

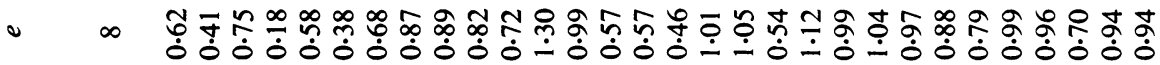

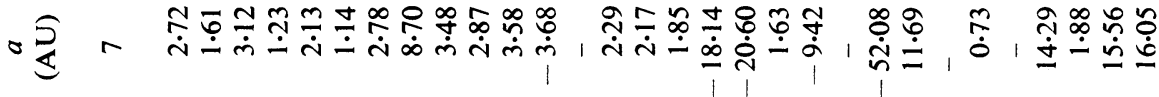

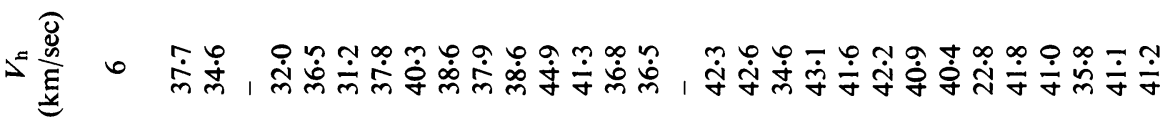

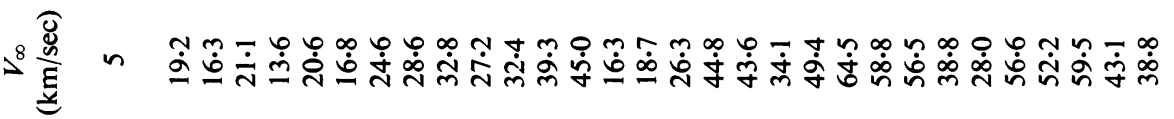

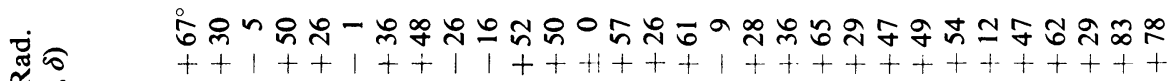

$++1++1++11+++1+++1+t++++++++++t$

$\underbrace{\infty}_{0}+$

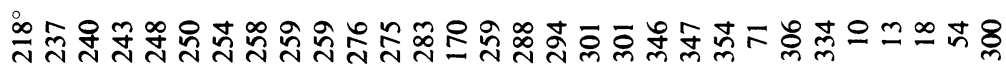

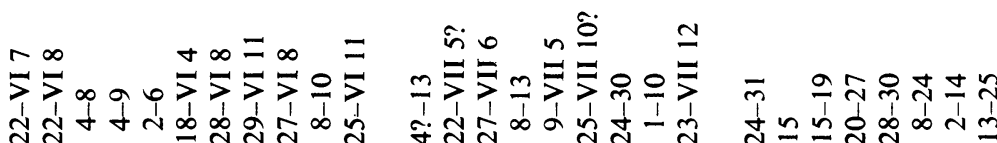

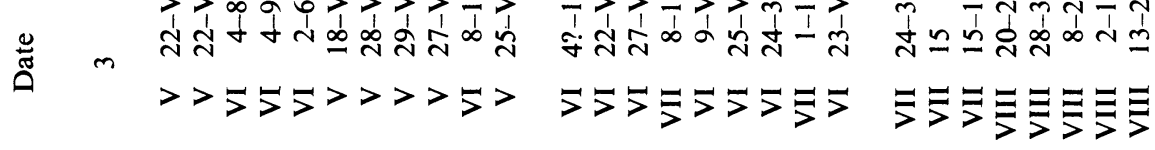

తิอ

తอ

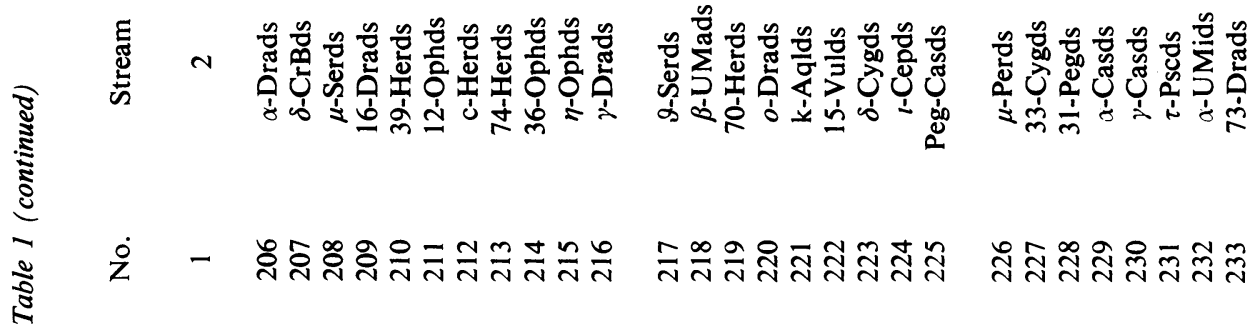




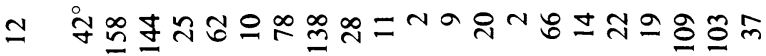

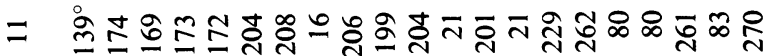

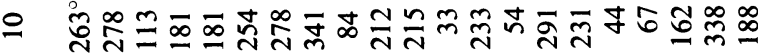

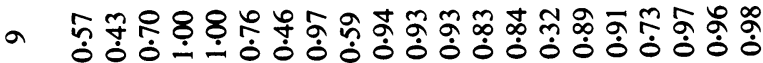

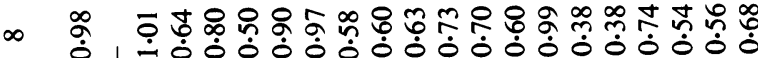

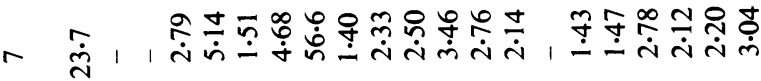

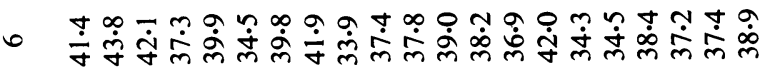

n

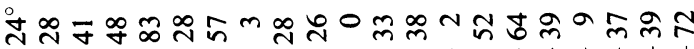

$\forall$

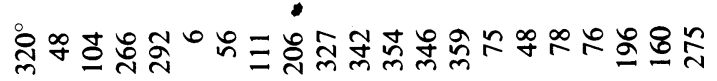

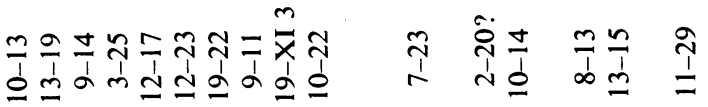

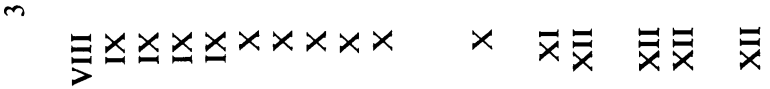

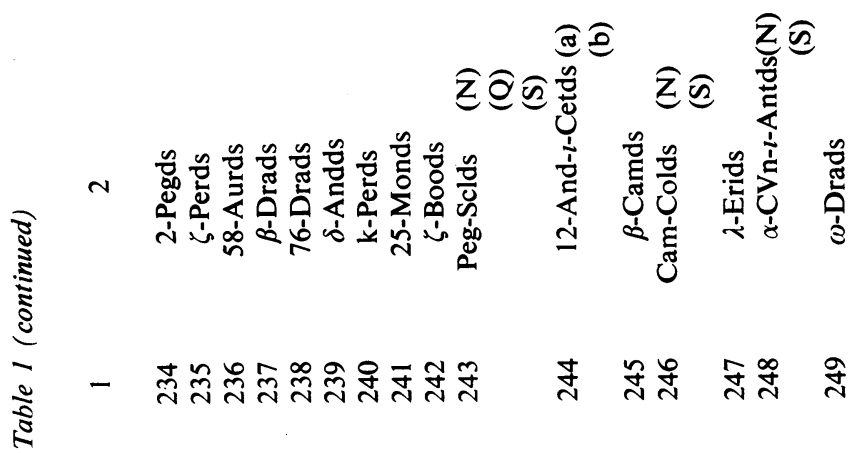




\section{Table 2}

\section{Photographic and visual observation data sources \\ for 95 minor meteor streams}

\begin{tabular}{|c|c|c|c|}
\hline $\begin{array}{l}\text { Stream } \\
\text { No. }\end{array}$ & $\begin{array}{l}\text { Photographic } \\
\text { data }\end{array}$ & $\begin{array}{l}\text { Visual } \\
\text { data }\end{array}$ & Notes \\
\hline 1 & 2 & 3 & 4 \\
\hline 155 & $6062,6231(1)$ & $176(16), 4(17)$ & $\begin{array}{l}\text { Shower of slow fireballs. } \\
\text { See } 6298 \text { (1) }\end{array}$ \\
\hline 156 & $\begin{array}{l}\text { (a): } 9875,6125(1) \\
\text { (b): } 9895,6160 \text { (1) }\end{array}$ & $140,164(16)$ & \\
\hline 157 & $9900,6227(1)$ & & \\
\hline 158 & $10070(2), 6199$ (1) & & \\
\hline 159 & $6116,6270(1)$ & & \\
\hline 160 & $6260,6296(1)$ & & \\
\hline 161 & $10031,6312(1)$ & & $284(16)$ \\
\hline 162 & $10007,6206(1)$ & & \\
\hline 163 & $\begin{array}{l}9891,6154,6239,6251,6262 \\
6282,6302,6310(1), 1992(3)\end{array}$ & $\begin{array}{l}391^{\mathrm{a}}(16) \\
10^{\mathrm{a}}, 25(17)\end{array}$ & Broad stream \\
\hline 164 & $10001,6320(1)$ & & $10022(4)$ \\
\hline 165 & $6193,6340(1)$ & & \\
\hline 166 & $\begin{array}{l}\text { (a): } 12765,6393,13295,13299 \\
6405(1), 630574(5) \\
\text { (b): } 12233,12680,12682(1)\end{array}$ & & \\
\hline & (c): $6387,6491(1)$ & & $\begin{array}{l}\text { Obvious connection with } \\
\text { stream } 15(15)\end{array}$ \\
\hline 167 & $12672(1), 630584(5)$ & & \\
\hline 168 & $6416,6469(1)$ & & \\
\hline 169 & $12239,4020(1), 109(6)$ & $544(16), 41(17)$ & $\begin{array}{l}\text { Possible connection with } \\
\text { stream } 25 \text { (15) }\end{array}$ \\
\hline 170 & $6426,6525(1)$ & & \\
\hline 171 & $12643(4), 6516(1)$ & & $\begin{array}{l}\text { Possible connection with } \\
\text { stream } 25(15)\end{array}$ \\
\hline 172 & $12225,13288(1)$ & & \\
\hline 173 & $6834,3054(1)$ & & $10215(1)$ \\
\hline 174 & $590541(6), 6795(1)$ & & \\
\hline 175 & $6770,6778,6805(1)$ & & \\
\hline 176 & $16789,7046(1)$ & & \\
\hline 177 & $6875,3076(1)$ & & \\
\hline 178 & $\begin{array}{l}\text { (a): } 6766,10208 \text { (1) } \\
\text { (b): } 6776,10270 \text { (1) }\end{array}$ & & \\
\hline 179 & $10237,10317(1)$ & & $6861(1)$ \\
\hline 180 & $3056,7040(1)$ & & \\
\hline 181 & $3058(1), 41(6)$ & 64 (19) & \\
\hline 182 & 2993,9809 (1) & $25(18)$ & \\
\hline 183 & 7026,7044 (1) & $545(16), 61(17)$ & $7049(1)$ \\
\hline 184 & 2913,3129 (3) & & \\
\hline 185 & $7252,7368(1)$ & & $292(16)$ \\
\hline 186 & $10478(1), 10365(2)$ & & \\
\hline
\end{tabular}


Table 2 (continued)

1

187

188

189

190

191

192

193

194

195

196

197

198

199

200

201

202

203

204

205

206

207

208

209

210

211

212

213

214

$215 \quad 12536(1), 2^{a}(9)$

$216 \quad$ (a): 4092,12140 (1)

(b): $7731,12572(1)$

$217 \quad 7806,12561(1), 20131$ (7)

$218 \quad 4141$ (2), $123(6)$

$219 \quad 591774(6), 12874$ (1), 7946 (2)

220

(a): 7110,7207 (1)

(b): 10542, 7367 (1)

10524, $7118(1)$

: 7237,7244 (1)

7291,7385 (1)

$1071(3), 114$ (6)

$7161,10094(1)$

(a): 11188,11960 (1)

(S): 3251 (1), 11825 (2)

$\left(\mathrm{N}^{\prime}\right): 7465,7471(1)$

11198, 7535 (1)

11797, 11991 (1)

8093 (7), 11865 (1)

3244, 11996, 7641 (1)

(a): 7598, 12068 (1)

(b): 11970,11994 (1)

(c): 11838 (1); (8)

3307,12515 (1)

$3300,12382,12532(1)$

7729 (1), 7788 (4)

12490,7821 (1)

12405, 7777 (1)

7688,12468 (1)

12292, 7790 (1) 7959 (4)
7179,7265 (1)

(b): $11168,11206,7504,7529$ (1)

(N): 11786,11824 (1)

3268 (1)

139 (19)

$410(16)$

$668(16)$

417 (16)

$680(16)$
3

4

$7324(1)$

7254 (1), 484 (16)

$10430(1)$

$7155(1)$

$93(19)$

$7661(1)$

$7562(1)$

Possible connection with stream 65 (15). See

7587 (1)

7457 (1)

$6(17$, Table 1$)$

$10147(1)$

$7524(1)$

$12326(1)$

Possible connection with stream 77 (15)

12495 (1)

$10589(1)$

Probable connection with stream 76 (15)

See streams 86 and $96(15)$.

See also 12448 (1),

577 (16), 145 (17)

679 (16)

$12370(1)$

$7941(1)$

a The value $q-0.330$ in paper (9) is erroneous. 
Table 2 (continued)

\begin{tabular}{|c|c|c|c|}
\hline $\begin{array}{l}\text { Stream } \\
\text { No. }\end{array}$ & $\begin{array}{l}\text { Photographic } \\
\text { data }\end{array}$ & $\begin{array}{l}\text { Visual } \\
\text { data }\end{array}$ & Notes \\
\hline 1 & 2 & 3 & 4 \\
\hline 221 & $12620(1)$ & $\begin{array}{l}130^{\mathrm{a}}(17), 159 \\
170(19)\end{array}$ & \\
\hline 222 & $12886(1), 124(6)$ & $716(16)$ & \\
\hline 223 & $12722(1)$ & $701(16), 137(17)$ & \\
\hline 224 & $1(11), 20712(7)$ & & \\
\hline 225 & $\begin{array}{l}\text { (a): } 4177(1), 120(6) \\
\text { (b): } 4196(1), 3601(10), \\
20531(7)\end{array}$ & & \\
\hline 226 & $3491(1)$ & $\begin{array}{l}164(19) \\
197(16), 94(18)\end{array}$ & \\
\hline 227 & $8018(1), 44(6)$ & & \\
\hline 228 & $8028,3356(1)$ & & $788(16)$ \\
\hline 229 & $156(6), 5(9)$ & $25(16)$ & $8581(1)$ \\
\hline 230 & $19^{\mathrm{b}}(6), 3861(1)$ & & $231(19)$ \\
\hline 231 & $64,582652(6)$ & $38,63(16)$ & $61(16), 64(6)$ \\
\hline 232 & $620511(5), 8215(2)$ & $180(16)$ & \\
\hline 233 & $8464,3800(1)$ & & $713(16)$ \\
\hline 234 & $2073(3), 582624 \mathrm{~b}(6)$ & & $778(16)$ \\
\hline 235 & $43(12), 85^{\mathrm{c}}(6)$ & $166(16)$ & $149(18), 4586(1)$ \\
\hline 236 & $612992(5), 2450(3)$ & & \\
\hline 237 & $4513,4528(1), 621234(5)$ & & $\begin{array}{l}\text { Possible connection with } \\
\text { stream } 126(15) \text {. See } \\
593(16), 230(17)\end{array}$ \\
\hline 238 & $583135(6), 4341,4380(1)$ & & $227(17), 4677(1)$ \\
\hline 239 & $9039,5159(1)$ & & \\
\hline 240 & 4930, $5091(1)$ & & $220(16), 267(17)$ \\
\hline 241 & $621973(5), 23271(7)$ & & \\
\hline 242 & (13) & $525(16)$ & Shower of fireballs \\
\hline 243 & $\begin{array}{l}(\mathrm{N}): 4734,4787(1), 583777(6) \\
(\mathrm{Q}): 1514(3), 5058(1) \\
(\mathrm{S}): 4791(1)\end{array}$ & & $622215(5), 9107(1)$ \\
\hline 244 & (b): $4926,4842(1), 124 a(14)$ & & $\begin{array}{l}\text { Possible connection with } \\
\text { stream } 131(15) \text {. See } \\
10941(7) \\
4905,5047 \text { (1) }\end{array}$ \\
\hline 245 & $9149,9311(1), 584591 \mathrm{a}(6)$ & 249 (16), 309 (17) & $\begin{array}{l}\text { See (15): stream No. } 143 \text {. } \\
\text { See also } 280,287 \text { (17) }\end{array}$ \\
\hline 246 & $\begin{array}{l}\text { (N): } 5876,5935(1) \\
(\mathrm{S}): 5587,9735(1)\end{array}$ & & $\begin{array}{l}134(16), 321(17) \\
320(17)\end{array}$ \\
\hline 247 & $614715(5), 5742,5880(1)$ & & $9387,9406(1)$ \\
\hline 248 & $\begin{array}{l}(\mathrm{N}): 5864(1) \\
(\mathrm{S}): 9789(1)\end{array}$ & & $448(16)$ \\
\hline 249 & $622713(5)$ & $615(16)$ & \\
\hline
\end{tabular}

a Radiant see in note to No. 130 (17).

b Date misprint: instead of ' 57 VIII 18.843' read '57 VIII 28.843'.

c Date misprint: instead of ' $58 \mathrm{XI}$ ' read ' 58 IX'. 
meteor particles becomes very low, so that the hourly numbers drop below $0 \cdot 3$, the shower becomes undetectable. But if the minor shower is sufficiently active, and its width considerable, then the above is confirmed.

A considerable number of minor meteor streams undergo comparatively fast evolutionary changes. This necessitates their constant re-observation - a sort of minorshowers service. The rate of stream evolution is determined by a number of causes and depends on the spatial location of the orbit with regard to the orbits of the large planets and the possibility of close approaches to them. For example, preliminary studies of the radiants of minor showers which are known to-day, compared to observations of ancient times, indicate that long-period streams with great inclinations undergo no significant changes over the period of a millennium; whereas short-period ecliptical streams with aphelia in the vicinity of Jupiter's orbit evolve from a compact stream to a dispersed association within a period of several hundred years, and some of them undergo these changes in less than a century.

It is important to know each minor stream as fully as we know any of the great streams recognized at present. It is only natural that more attention is paid to the most prominent minor streams, of which there are several scores. One of the major problems for investigation is the study of stream structure, its dynamic development and general evolution.

In many cases we observe now only relics of once great streams. In some cases there is almost no doubt that the minor streams originate from great ones, or from comets corresponding to great streams. It is necessary to clarify precisely by means of the numerical methods of celestial mechanics the process of stream disintegration due to the perturbing effect of the outer planets, and to explain the formation in the stream of separate branches and groups as, well as other observable phenomena.

Photographic observational data available at present are unfortunately far from comprehensive: the required 3-year observation cycle (to avoid lunation effect) has not been adhered to; there is not sufficient observation during the pre-dawn hours; the Baker Super-Schmidt cameras are installed only on one of the continents. It is, therefore, clear that for a comprehensive study of the minor streams the number of photographic orbits should be increased by at least one order of magnitude. In addition to this, the solution of a series of problems in the field of meteor astronomy by the methods of celestial mechanics requires a drastic increase (by at least three orders of magnitude) in the precision of determining the elements of meteor orbits, so that

Note:

References to Table 2 are marked as follows: (1) - McCrosky and Posen (1961); (2) - Jacchia and Whipple (1961); (3) - Whipple (1954); (4) - Hawkins and Southworth (1958, 1961); (5) Babadžanov et al. (1966); (6) - Babadžanov and Kramer (1963); (7) - Ceplecha et al. (1964); (8) Ceplecha (1952); (9) - Katasev (1950); (10) - Ceplecha (1958); (11) - Demjanenko et al. (1964); (12) - Katasev (1957); (13) - Ceplecha and Rajchl (1965);(14) - Plavcová and Plavec (1960); (15) Terenteva (1966); (16) - Astapovič (1956); (17) - Astronomical Yearbook (1962); (18) - Proskurina (1949); (19) - Proskurina (1957). 
the velocity values can be obtained with an accuracy of $0 \cdot 1 \mathrm{~m} / \mathrm{sec}$ and the orbital elements with an accuracy to the sixth decimal.

\section{On the Connection between Minor Meteor Streams and Comets}

The problem of investigating the connection between a meteor stream and a comet can be solved by using the method of numerical integration of the differential equations of motion of meteor bodies, and by following this motion backward, to the moment when the distance between the given body and the comet becomes zero. A detailed study of the perturbed motion of a great number of meteor particles must be carried out for a sufficiently great space of time, a millennium or more. But as long as the techniques for the determination of meteor velocities do not ensure sufficient accuracy, as has been pointed out above, this problem must be postponed to the future. The solution of such problems will depend on the results of a search for the most probable connection between meteor streams and comets.

Considering theoretical comet radiants (Kramer, 1953), and taking into account the history of the comet and the given stream and applying Tisserand's criterion, we suspect a connection between some comets and groups of minor streams. We have already reported on one of such comet-meteor families (Terenteva, 1966b). We give here an example of a possible connection between the well-known comet Lexell 1770-I and five minor streams: Ophiuchids (Northern and Southern), $\xi$-Serpentids, Scutids, $\gamma$-Scutids, and $\eta$-Aquilids. The author mentioned formerly (1965) a connection between the $\alpha$-Capricornids and this comet. Table 3 (see also Figure 1) shows the orbital elements of the comet, according to Porter's catalogue (1961), and of five meteor streams, according to a paper by the author (1966a). The last column contains the value $C$ of Tisserand's constant. $C$ is taken for the streams as the mean from $n$ values ( $n$ being the number of individual orbits in the stream) with arithmetical mean deviations.

As it is well known, comet Lexell catastrophically changed its orbit under the influence of perturbations at near approaches to Jupiter in 1767 and 1779; in 1770 it had an exceptionally close approach to the Earth, $q$ being $=0.67 \mathrm{AU}, \Delta=0.015 \mathrm{AU}$ (Kazimirčak-Polonskaja, 1961), owing to which it was detected with absolute stellar magnitude $+7 \cdot 7$.

Not a single comet of Jupiter's group approached the Earth within such a small distance. Great perturbations caused by a close approach to Jupiter in 1779 moved the comet's orbit away from the Earth's, and since that time the comet had not been observed. The streams in question may have remained as relics of this comet, and the corresponding showers continue to be observed, but with a large spread in the date of activity (June-August) and in the position of radiants (up to $45^{\circ}$ ). It should be noted, that the similarity of physical properties of the meteors in these showers always amazed observers, like e.g. Denning and Astapovič. Pokrovsky (1901), in his unfin- 
Table 3

Possible family of minor meteor streams associated with comet Lexell 1770-I (Equinox 1950.0)

Comet and meteor streams

Lexell (1770-I)

North Ophiuchids (94) 16 VI-3 VII

South Ophiuchids (94) 16 VI-3 VII

$\xi$-Serpentids (95)

22 VI-6 VII

Scutids (96)

$12-29 \mathrm{VI}$

$\gamma$-Scutids (114)

5-14 VIII

$\eta$-Aquilids (117)

1-16 VIII

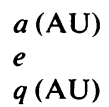

$\mathbf{0 . 7 8 6}$

0.674

2.74

0.712

0.763

3.48

0.770

0.793

2.86

0.758

0.678

$3 \cdot 24$

0.848

0.482

2.65

0.645

0.935

3.04

0.740

0.783 $\pi$
$\boldsymbol{i}$
$i$

$358^{\circ} .8$

133.9

1.6

$336 \cdot 8$

89.9

6.9

$338 \cdot 7$

$278 \cdot 0$

4.0

$352 \cdot 7$

$95 \cdot 2$

$5 \cdot 5$

$10 \cdot 0$

91.8

$9 \cdot 2$

$350 \cdot 0$

133.0

$3 \cdot 0$

$15 \cdot 0$

$133 \cdot 0$

$13 \cdot 5$

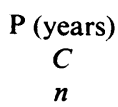

5.60

0.5020

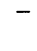

$0.57 \pm 0.05$

4

$0.49+0.04$

3

$0.54+0.04$

4

$0 . \overline{47}+0.04$

4

$\overline{0.59} \pm 0.03$

2

$0.52 \pm 0.01$

2

ished monograph, noted a probable connection of comet Lexell with the periodic comet Finlay, 1960-VIII $(C=0.5033 \pm 0.0002)$. A relation may perhaps exist between these two comets and comet Barnard (3), 1892-V.

In Table 4 nine of the streams, Nos. 155-249 from the list cited above, are linked with comets (Porter, 1961) with which they may be physically connected.

As in the case of the great streams, the period of revolution of a minor stream is less than the period of revolution of the comet connected with it. If the great comet Flaugergues 1811-I was really 'great', and can be connected with the stream No. 226, his had a width of $0.6 \mathrm{AU}$. In the rest of the cases, for an encounter with the Earth to be possible, the width of the stream must be at least $0.01-0.15 \mathrm{AU}$ judging from values of $q$, and at least $0.02-0.29 \mathrm{AU}$, if we take into account the differences in $\Omega$. A connection between streams Nos. 193 and 240 has been pointed out in the foregoing section.

Favourable conditions in the examples cited are the great value of the inclination $i$ of the stream, and the nearly parabolic character of the orbits of the comets, permitting easy identification. In this case the influence of planetary perturbations is 


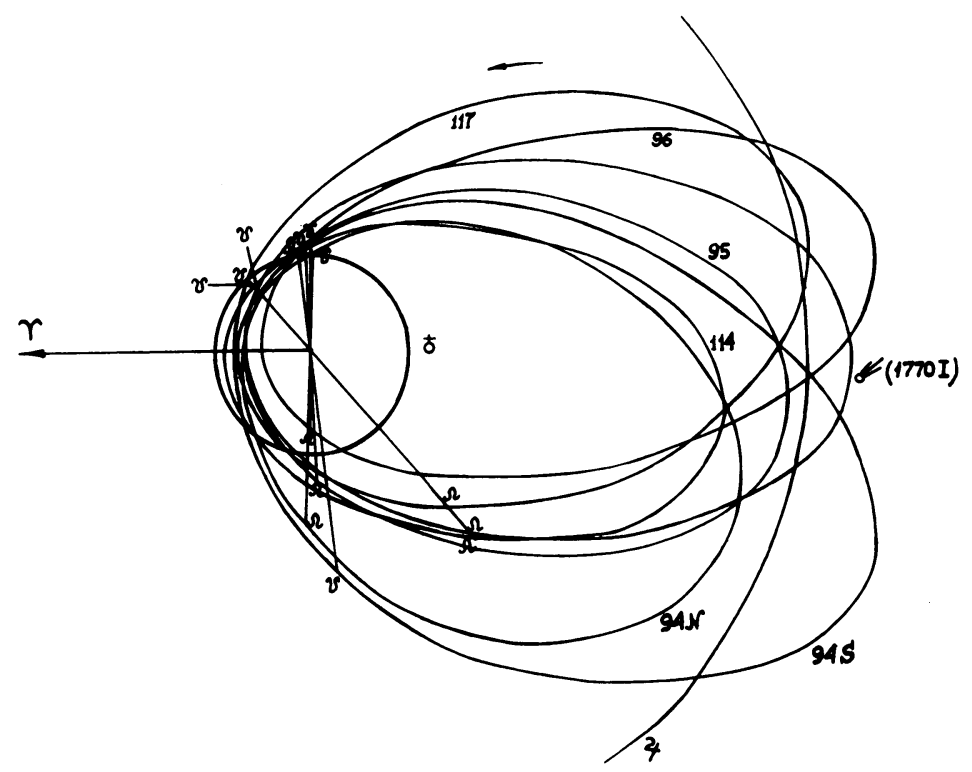

FIG. 1. Possible family of minor meteor streams associated with comet Lexell 1770-I (projection on the ecliptic plane).

\section{Table 4}

\section{Correspondence between minor streams and comets}

\section{(Equinox 1950.0)}

\begin{tabular}{|c|c|c|c|c|c|c|}
\hline Stream and comet & $i$ & $\Omega$ & $\omega$ & $q(\mathrm{AU})$ & $e$ & $a(\mathrm{AU})$ \\
\hline Stream 169 & $109^{\circ}$ & $324^{\circ}$ & $220^{\circ}$ & 0.87 & 1 & - \\
\hline Comet 1947-X & 106 & 312 & 221 & 0.75 & 1 & - \\
\hline Stream 172 & 44 & 316 & 142 & 0.90 & 0.77 & 4.06 \\
\hline Comet 1854-IV & 41 & 326 & 130 & 0.80 & 0.992 & 106 \\
\hline Stream 193 & 80 & 20 & 112 & 0.68 & 1 & - \\
\hline Comet 1886-I & 83 & 37 & 127 & 0.64 & 1 & - \\
\hline Stream 202 & 108 & 32 & 217 & 0.92 & 0.65 & $2 \cdot 66$ \\
\hline Comet 1864-III & 110 & 33 & 232 & 0.93 & 0.999 & 1451 \\
\hline Stream 225 (a) & 126 & 95 & 192 & 1.00 & 0.99 & 100 \\
\hline Comet 1822-IV & 127 & 95 & 181 & $1 \cdot 15$ & 0.996 & 310 \\
\hline Stream 226 & 109 & 126 & 77 & 0.41 & 0.97 & 11.7 \\
\hline Comet 1811-I & 107 & 142 & 65 & 1.04 & 0.995 & 212 \\
\hline Stream 229 & 103 & 152 & 243 & 0.73 & 0.99 & 73 \\
\hline Comet 1871-IV & 98 & 148 & 243 & 0.69 & 0.996 & 162 \\
\hline Stream 232 & 69 & 131 & 142 & 0.91 & 0.94 & $15 \cdot 6$ \\
\hline Comet 1737-II & 62 & 135 & 130 & 0.83 & 1 & - \\
\hline Stream 236 & 144 & 169 & 113 & $0 \cdot 70$ & 1 & - \\
\hline Comet 1790-I & 150 & 175 & 114 & 0.75 & 1 & - \\
\hline
\end{tabular}


comparatively small. If the connection of these streams with comets is real, we must admit the possibility of the existence of meteor streams formed by comets with exceedingly elongated orbits to thousands of AU and more. Possibly, with sufficiently long periods of revolution (scores of millenniums) these nearly parabolic comets may be accompanied by meteor streams reaching a considerable width, of the order of the distance of the Earth from the Sun. This means that, in passing the perihelion of such a stream, the Earth's orbit may be entirely inside it. Schiaparelli calculated that the passage of such a stream may take centuries, owing to the difference in solar attraction on its nearest and remotest parts. Hence, during a year, the Earth can continuously encounter meteors from the stream; its geocentric radiant will describe a closed curve in the sky, and the geocentric velocity will change smoothly. Knowing the direction towards the aphelion of the stream and the nearly parabolic stream velocity, we can obtain an ephemeris of the geocentric radiant and the corresponding velocity, and compare them with observations. The density of meteor particles may be different in various parts of the stream, and here and there it may be zero. A more detailed examination of this matter is of interest.

\section{Cyclids and the Perturbed Motion of one of these Meteor Bodies}

It is well known that meteor bodies whose orbits almost exactly coincide with the Earth's orbit have been detected by the photographic method. Southworth and Hawkins (1963) give five such orbits, and all the meteor bodies moving in these orbits they conventionally name 'Cyclids'.

Table 5 contains information on $\$ 30$ Cyclids, found by us in the Catalogue of McCrosky and Posen (1961); in other sources, comprising more than 1000 photographic orbits, such meteors have not been detected. Therefore we limit ourselves to eccentricities $e \leqslant 0 \cdot 14$, aphelion distances $q^{\prime} \leqslant 1 \cdot 2 \mathrm{AU}$ and inclinations $i \leqslant 15^{\circ}$.

Obviously, the Cyclids do not constitute some physical system in which the bodies are united by common nature and origin as is the case for ordinary meteor streams. They are an example of a set of evolving orbits, selected by their current similarity with the Earth's orbit. The ways by which this similarity is attained may be quite different for each orbit. It may be assumed that such physical factors in the orbit's perturbations, as the effects of Poynting-Robertson and Radzievskij, leading to a decrease of the semi-major axis and the eccentricity, are of great importance in this evolution.

A spiral-forming, nearly circular orbit changes gradually from value of $a>1$ to $a<1$; the place of particles passing nearer the Sun is taken by new particles from the external regions, so that the Cyclids' 'system' remains in dynamic equilibrium.

The Cyclids possess unique properties, not encountered anywhere else in meteor astronomy. The difference between the heliocentric velocities of the Cyclids and the Earth is very small, therefore their observed geocentric (extra-atmospheric) velocity is 


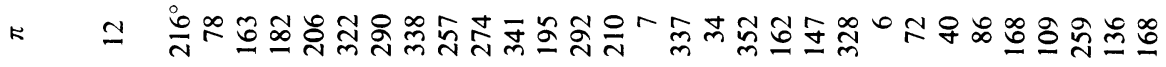

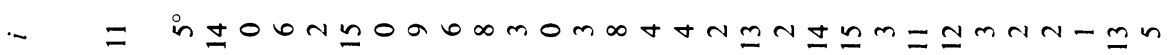

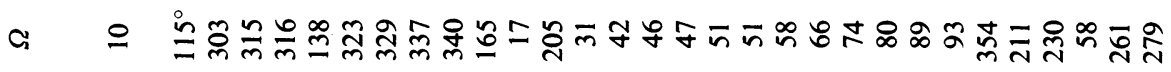

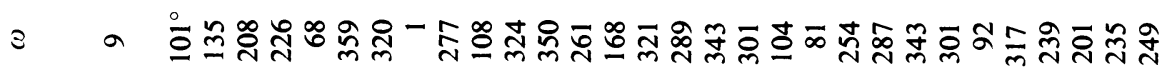

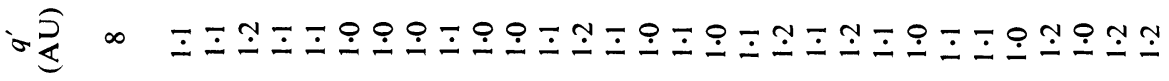

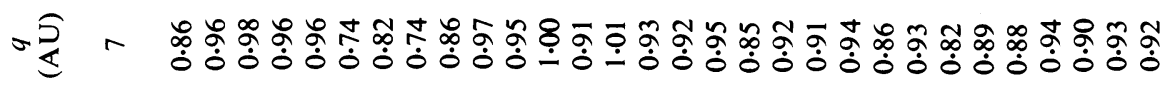

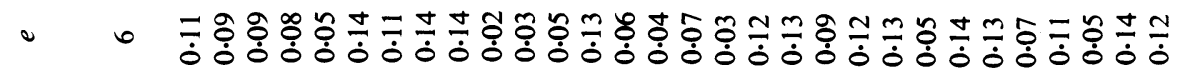

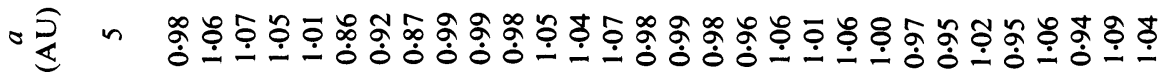

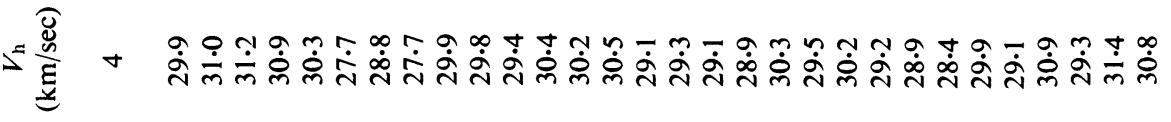
د若

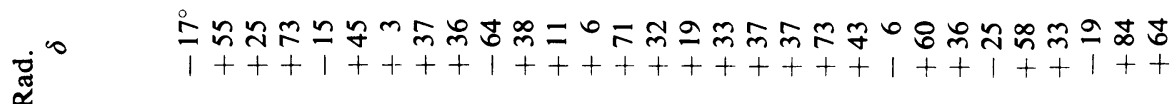
䓂.

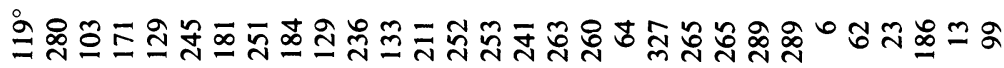

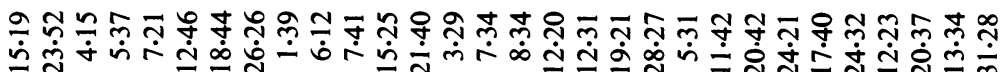
苋 -

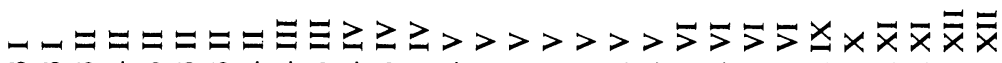

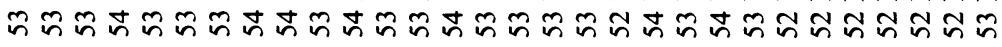


near the parabolic limit. The geocentric radiants of the Cyclids are distributed over the whole area of the celestial sphere, displaying no regularity, although the heliocentric radiants may be fairly compact. Cyclids can be observed all through the year.

Our aim is to investigate the perturbed motion of one of the Cyclid meteor bodies over a space of time of several scores of orbital revolutions. The investigation has been based on the orbit of the meteor body No. 4084 (Hawkins and Southworth, 1958, 1961), shown together with other orbits of the Cyclids in Figure 2.

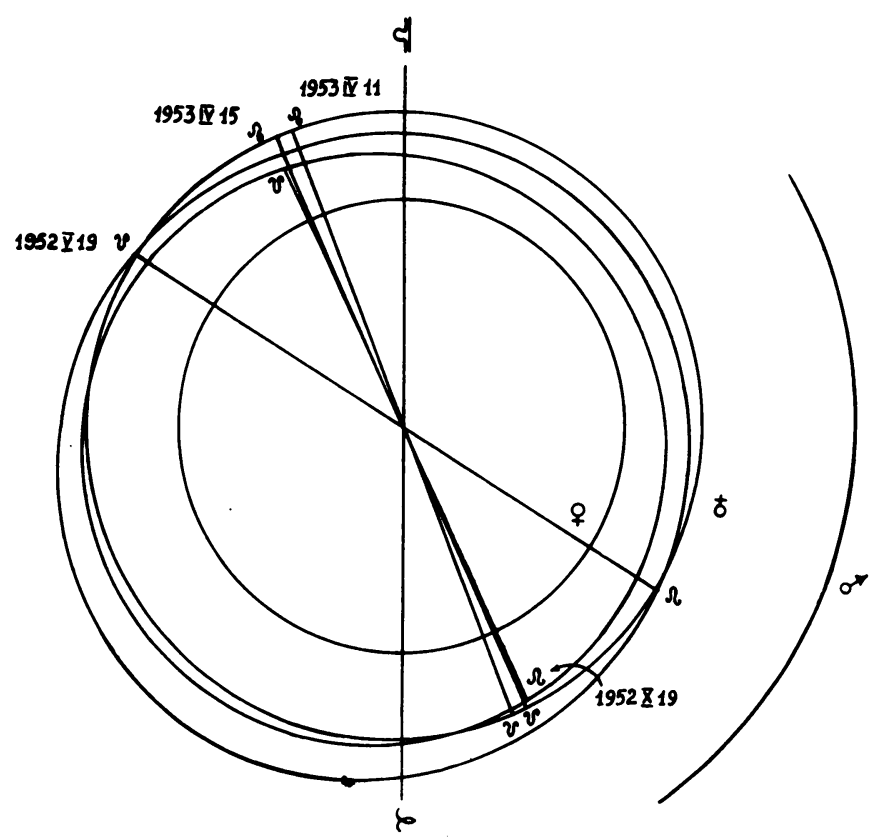

Fig. 2. Orbits of four Cyclid meteor bodies. 1952 V 19 - No. 4084 (Hawkins and Southworth, 1958, 1961); $1952 \times 19$ - No. 4952 (Jacchia and Whipple, 1961); 1953 IV II; 1953 IV 15 - (Southworth and Hawkins, 1963).

We assumed the following initial system of elements:

$$
\begin{aligned}
& T=1952 \text { May } 18 \cdot 0 \mathrm{ET}
\end{aligned}
$$

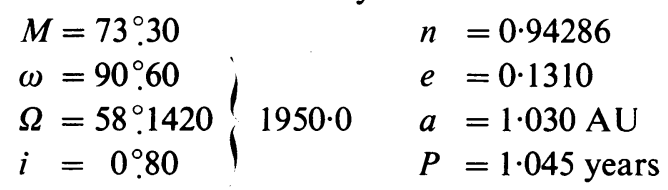

Numerical integration of the differential equations of motion of the given meteor body has been performed on the electronic computer BESM-2 by Cowell's method of quadratures taking accurate account of perturbations from six planets (Venus- 


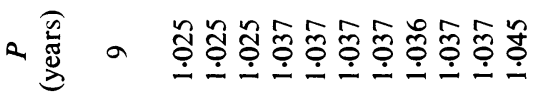

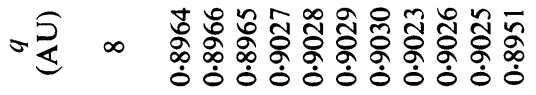

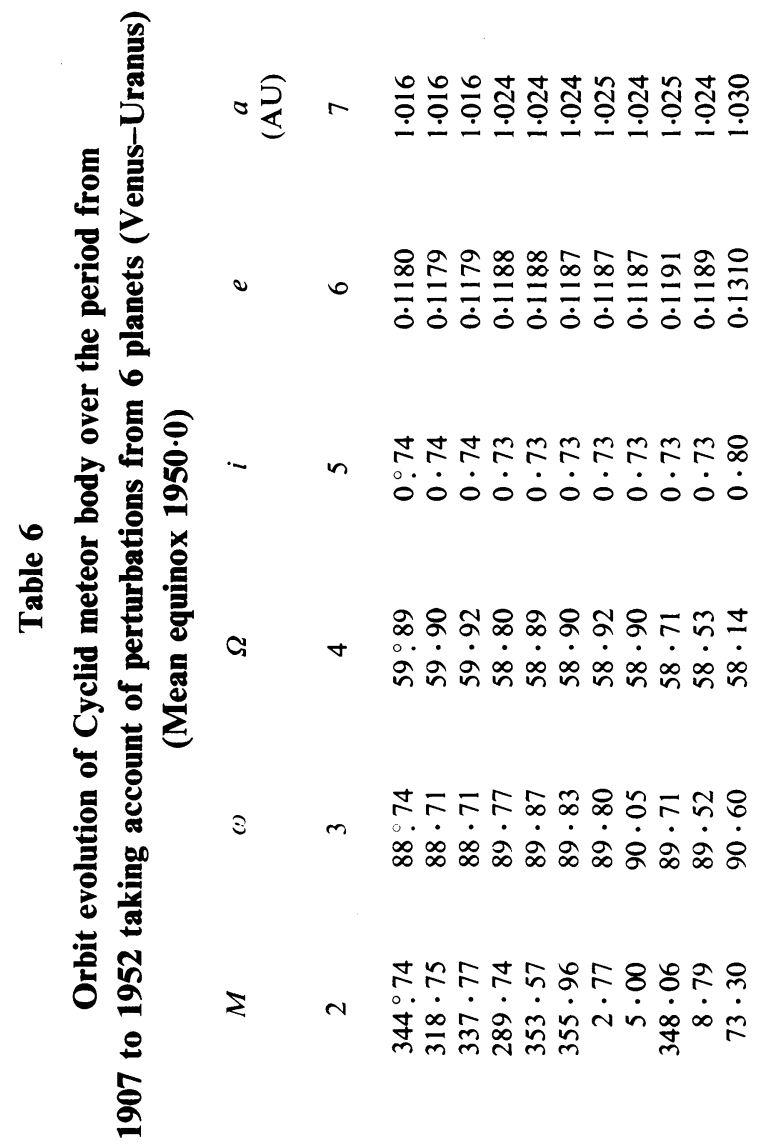

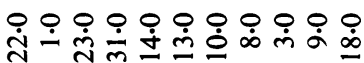

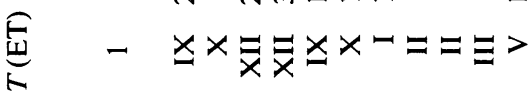

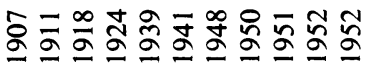


Uranus) and of high-order terms through to the 4th order. The program of integration is reported in Beljaev's paper (1967). The integration has been carried out in three approximations, with eight decimals and a variable step. The computations have been performed at our request by Beljaev (Institute for Theoretical Astronomy, Leningrad), to whom the author is greatly indebted.

The motion of this meteor body has been investigated for the time-interval from 1952 backward to 1907. The integration results are listed in Table 6. The epochs of osculation, $T$, are shown in the first column, the following columns contain the corresponding osculating elements: mean anomaly, $M$, perihelion argument, $\omega$, longitude

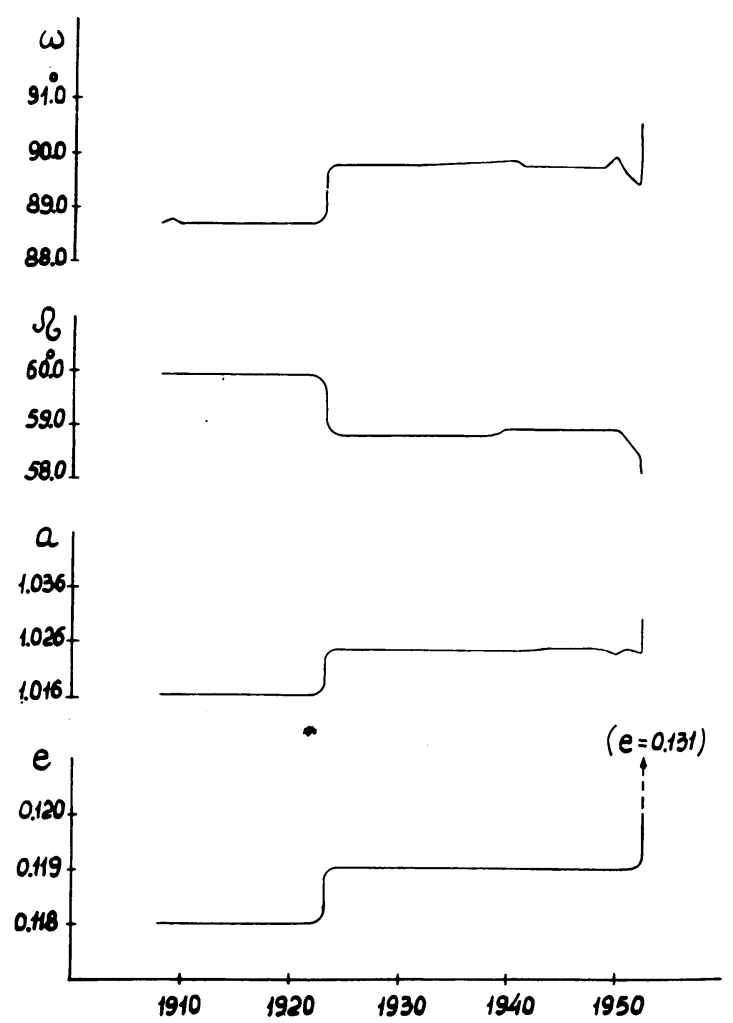

FIG. 3. Evolution of the orbital elements $\omega, \Omega, a$ and $e$ of a meteor body of the Cyclids for the period from 1907 to 1952, taking account of perturbations from six planets (Venus-Uranus).

of the ascending node, $\Omega$, inclination, $i$, eccentricity, $e$, semi-major axis, $a$, perihelion distance, $q$, and period of revolution, $P$.

Figure 3 shows the evolution of the orbital elements, $\omega, \Omega, a$ and $e$ of the meteor body for the period of time studied.

The perturbing actions on the part of Venus are practically imperceptible. The 
Cyclid approached Venus to a minimum distance $\Delta=0 \cdot 2052$ AU in 1950 , March $5 \cdot 0$. All the more or less perceptible perturbations (see Figure 3) in the motion of the Cyclid are caused by the Earth, but the influence of these is practically negligible. Approaches to the Earth at $\Delta=0.0949 \mathrm{AU}(1950$, October 26.0) and $\Delta=0.0787 \mathrm{AU}$ (1951, January 29.0) led to changes in the angular orbital elements of the Cyclid by not more than $0^{\circ} .3$, and by +0.0012 part of a year in the revolution period. Changes in the angular elements do not exceed about $1^{\circ}$, even for penetrations into the Earth's sphere of action to a distance of the order of $0.003 \mathrm{AU}$.

The following limits of changes in the Cyclid's orbital elements have been found for the interval 1907-52, taking account of perturbations from six planets (Venus-

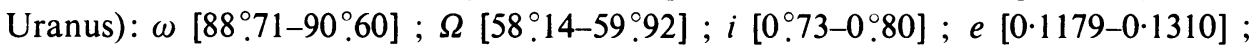
$a[1.016-1 \cdot 030] ; q[0.8951-0.9030] ; P[1.025-1 \cdot 045]$.

From the above it follows that for the period of time under investigation, the orbit of the Cyclids remains stable.

It can be assumed that the perturbing action of the Earth on meteor bodies like the Cyclids does not lead to important changes in their orbits for approaches of the type discussed here. However, at deeper penetrations into the Earth's sphere of action, the meteor bodies may experience considerable perturbations.

Further conclusions about the evolution of orbits of the Cyclid meteor bodies necessitate the studies of the motion of a great number of objects over a long time period.

\section{References}

Astapovič, I.S. (1956)

Main Catalogue of 19th Century Meteor Radiants, Ašhabad, Akad. Nauk Turkmen. SSR.

Astronomical Yearbook (Permanent Part) (1962) 5th edition, Fizmatgiz, Moskva, p. 616.

Babadžanov, P. B., Kramer, E. N. (1963) Rezultaty Issled. MGG - Ionosfera i Meteory, No. 12, 1. Babadžanov, P.B., Suslova, N.N., Karaselnikova, S.A. (1966) Bjull. Inst. Astrofiz., Dušanbe, 41-42, 3.

Beljaev, N. A. (1967) Bjull. Inst. teor. Astr., Leningrad, 10, 696.

Ceplecha, Z. (1952) Bull. astr. Inst. Csl., 3, 13.

Ceplecha, Z. (1958) Bull. astr. Inst. Csl., 9, 225.

Ceplecha, Z., Rajchl, J. (1965) Bull. astr. Inst. Csl., 16, 15.

Ceplecha, Z., Ježková M., Novák, M., Rajchl, J., Sehnal, L. (1964) Bull. astr. Inst. Csl., 15, 144.

Demjanenko, V.I. et al. (1964) Inf. Bjull. MGG, Kiev, 6, 32.

Hawkins, G.S., Southworth, R.B. (1958) Smithson. Contr. Astrophys., 2, 349.

Hawkins, G.S., Southworth, R. B. (1961) Smithson. Contr. Astrophys., 4, 85.

Jacchia, L.G., Whipple, F.L. (1961) Smithson. Contr. Astrophys., 4, 97.

Kazimirčak-Polonskaja, E.I. (1961) Trudy Inst. teor. Astr., 7, 1.

Katasev, L.A. (1950) Trudy astr. Obs., Stalinabad, 3, 7.

Katasev, L.A. (1957) Fotografičeskie Metody Meteornoj Astronomii, GITTL, Moskva.

Kramer, E.N. (1953) Izv. astr. Obs. gos. Univ., Odessa, 3, 163.

McCrosky, R.E., Posen, A. (1961) Smithson. Contr. Astrophys., 4, 15.

Plavcová, Z., Plavec, M. (1960) Bull. astr. Inst. Csl., 11, 226.

Pokrovsky, K.D. (1901) Origin of Periodic Comets, Part 1, Juriev.

Porter, J.G. (1961) Mem. Br. astr. Ass., 39, No. 3.

Proskurina, E. M. (1949) Izv. Akad. Nauk Turkmen. SSR, 3, 66. 
Proskurina, E. M. (1957) Trudy Inst. Fiz. i Geofiz. Akad. Nauk Turkmen. SSR, 3, 31. Southworth R. B., Hawkins, G.S. (1963) Smithson. Contr. Astrophys., 7, 261.

Terenteva, A.K. (1965) Bjull. Kom. Komet. Meteor, 11, 17.

Terenteva, A. K. (1966a) Rezultaty Issled. MGP - Issled. Meteorov, No. 1, 62.

Terenteva, A.K. (1966b) Problemy Kosmičeskoj Fiziki, Kiev, 1, 40.

Whipple, F.L. (1954) Astr. J., 59, 201. 